\title{
Radiation dosimetry by potassium feldspar
}

\author{
ARUN PANDYA*, S G VAIJAPURKAR and P K BHATNAGAR \\ Defence Laboratory, Jodhpur 342 011, India
}

MS received 12 July 1999; revised 15 February 2000

\begin{abstract}
The thermoluminescence (TL) properties of raw and annealed feldspar have been studied for their use in gamma dosimetry. The raw gamma exposed feldspar shows glow peaks at $120^{\circ} \mathrm{C}$ and $319^{\circ} \mathrm{C}$. Gamma dose beyond $500 \mathrm{cGy}$ can be measured without any significant fading even after 40 days of termination of exposure. The annealed feldspar shows a glow peak at $120^{\circ} \mathrm{C}$ after gamma exposure. This peak can be used to measure gamma doses beyond $25 \mathrm{cGy}$ when the TL is measured after $24 \mathrm{~h}$ from termination of exposure.
\end{abstract}

Keywords. Potassium feldspar; thermoluminescence; fading; glow curve.

\section{Introduction}

Quartz and raw sand have been widely used for measuring accident gamma dose by utilizing thermoluminescence property. Sand (a mixture of quartz, feldspar and heavy minerals) has been used to measure gamma radiation doses beyond 50 cGy (Vaijapurkar and Bhatnagar 1993). Feldspar which has been studied extensively exhibits thermoluminescence (TL) property (Wintle 1974; Clarke et al 1997). It is known that most of the feldspars are prone to anomalous fading (Wintle 1977), i.e. the unexpected loss of charge carriers responsible for high temperature TL. This makes them unsuitable for dating. The TL signals of feldspar show strong bleaching effect in sunshine (Duller 1997). The rate of bleaching varies from one sample to another. In alkali feldspars the TL peak height shifts towards higher temperature with time. This is interpreted as phototransfer from deeper traps (Robertson et al 1991). However, the $310^{\circ} \mathrm{C}$ TL peak in the glow curve of feldspar is useful for dosimetry (Mejdahl 1985). Feldspar has been reported to be about two orders of magnitude more sensitive than quartz to gamma radiation. Thus it is possible to detect lower gamma dose from feldspar (Ichikawa and Tanida 1969).

The present paper reports a study of TL of potassium feldspar granules. The potash pink grade $\mathrm{K} 20$ : (10 to $11 \% \mathrm{~min}$ ) was obtained from Indian Inorganics Ltd., Calcutta, India. The glow curve pattern of gamma exposed (raw and annealed) samples along with dose response and fading characteristics are discussed.

\section{Materials and methods}

Mejdahl (1968) reported that the TL output of Denmark seashore sand is independent of grain size. Later studies

*Author for correspondence have reported that desert sand shows optimum TL output when the grain size of $100-150 \mu \mathrm{m}$ is used (Vaijapurkar et al 1993). The feldspar (powdered to grain size 100$150 \mu \mathrm{m})$ was used in the present study. The feldspar was heated to $50^{\circ} \mathrm{C}$ for $1 \mathrm{~h}$ to remove the contribution of triboluminescence, if any, which is generated during powdering of the sample. About $100 \mathrm{mg}$ of processed feldspar sample wrapped in a tissue paper and covered with $0.5 \mathrm{~cm}$ thick Perspex cap for optimal build-up was exposed to gamma radiation using ${ }^{60}$ Co source. The TL generated by pouring the gamma exposed powder on hot plate showed bright blue flashes. Typical glow curve of gamma exposed feldspar samples were integrated between ambient temperature to $400^{\circ} \mathrm{C}$ using indigenous TLD reader.

The raw feldspar exhibits background TL signals due to exposure to natural radiation. Due to this TL background, the minimum dose which can be measured from natural feldspar sample is about $500 \mathrm{cGy}$. Therefore, the raw feldspar could detect gamma doses from $500 \mathrm{cGy}$ to $10^{6} \mathrm{cGy}$. Measurement of lower dose below $500 \mathrm{cGy}$ requires reduction of this background TL information. In order to remove the background TL information the feldspar was subjected to annealing at $500^{\circ} \mathrm{C}$. It is observed that annealing time of about $5 \mathrm{~min}$ is sufficient to eliminate background TL. The annealed samples could be used to measure doses of gamma radiation beyond 25 cGy.

The fading of TL information of gamma exposed raw and annealed feldspar samples have been studied. Before starting the experiment the TLD reader is calibrated with the help of a builtin light source every time. The feldspar samples were stored in a transparent glass vial at room conditions. The samples were not allowed any sunshine exposure to avoid the photobleaching effect. The TL signals emanated from gamma exposed feldspar were recorded at regular intervals to study the fading characteristics. 
Harshaw TLD reader was used for linearity and fading studies and the Nucleonix make TLD reader was used for glow curve analysis. The TL signal of gamma exposed feldspar sample were integrated from ambient temperature to $400^{\circ} \mathrm{C}$.

\section{Results and discussion}

Typical glow curves of raw unexposed and gamma exposed (1000 cGy dose) feldspar samples are shown in figure 1. It is observed that the processed unexposed sample indicates a glow peak at $319^{\circ} \mathrm{C}$ (curve 1), whereas the exposed sample (curve 2) exhibits a peak at $319^{\circ} \mathrm{C}$ and another at $120^{\circ} \mathrm{C}$. The low temperature trap centres are empty in raw feldspar sample before irradiation. It is due to fast fading of low temperature filled trap centres with time even at ambient temperature. Due to gamma exposure low temperature traps are reactivated. The reactivated traps have not faded significantly because the curves were recorded in a short time after termination of exposure. The storage of radiation energy in empty low temperature trap centres are more easier than deeply situated empty centres. Therefore, with gamma exposure the filling population of low temperature traps is more significant as compared to high temperature traps. The low temperature traps are almost empty and high temperature traps are significantly filled with earlier radiation stored information, i.e. background TL. The observation reported by Ichikawa and Tanida (1969) matches with our experimental findings, particularly, the total number of peaks and their intensity variations. The differences in findings are the position of glow peak, which is strongly dependent on heating rate and presence of impurities in the feldspar samples extracted from the sand.

Figure 2 shows the glow curves of annealed feldspar. The samples 1 and 2 were annealed at $500^{\circ} \mathrm{C}$ for $1 \mathrm{~h}$ and
$5 \mathrm{~min}$, respectively. It is evident that the annealing for $1 \mathrm{~h}$ and $5 \mathrm{~min}$, generates similar effect. The background TL is wiped out (curve 3). When the annealed samples are exposed to $1000 \mathrm{cGy}$ of ${ }^{60} \mathrm{Co}$ gamma dose, the TL glow peak is observed at $120^{\circ} \mathrm{C}$. For both the annealed samples the peaks are almost at the same temperature irrespective of annealing time (curves 1 and 2).

It is observed that the annealed feldspar samples does not show high temperature TL glow peak when exposed to gamma radiation. Thus low temperature TL traps are only sensitive at this dose level. Annealing bleaches the $319^{\circ} \mathrm{C}$ peak completely and only low temperature peak appears after gamma exposure.

Fading characteristics of exposed raw feldspar samples are depicted in figure 3 . The fading of TL was monitored for 1 week. It was observed that low temperature glow peak faded very fast initially, whereas the $319^{\circ} \mathrm{C}$ glow peak did not fade significantly. The integrated TL signal (in $\mu \mathrm{C}$ ) from ambient temperature to $400^{\circ} \mathrm{C}$ does not show any fading characteristic. Analysis of the glow curve indicates that with the fading of $120^{\circ} \mathrm{C}$ peak, the height of $319^{\circ} \mathrm{C}$ peak increases. The cause is unknown, but the phenomenon is reproducible. Thus the total information due to radiation is conserved. The low temperature peak shifting is also observed with time. The peak temperature shifting to higher temperature is interpreted as preferential bleaching of low temperature peak (Robertson et al 1993). Peak shifting is a phenomenon, which follows the fading of low temperature TL signals. The fading of TL signals at room temperature is treated as an isothermal decay. The fading in curve 2 , recorded $24 \mathrm{~h}$ after termination of exposure, is much more than the fading observed in subsequent hours (curves 3,4 ).

Figure 4 shows the TL fading of annealed feldspar exposed to $1000 \mathrm{cGy}{ }^{60} \mathrm{Co}$ gamma dose. The TL signal within $24 \mathrm{~h}$ after the termination of exposure is marked 2.

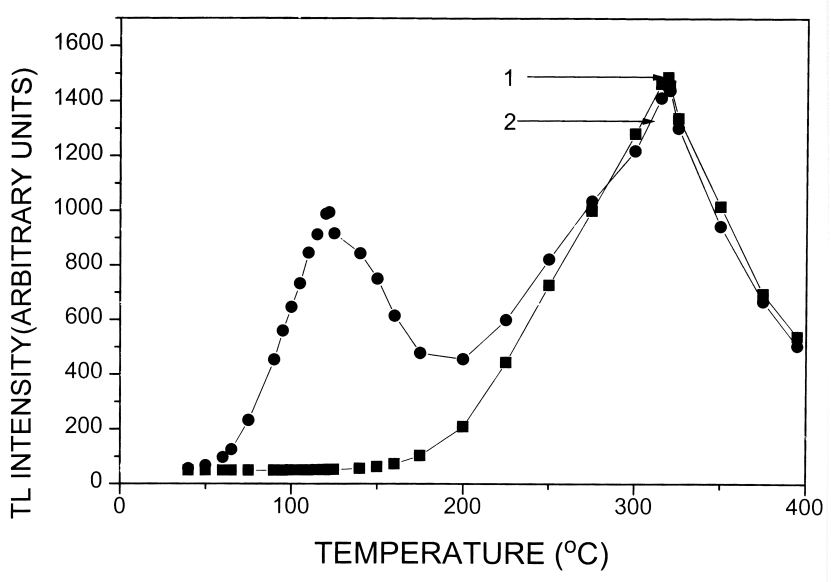

Figure 1. Glow curve of raw feldspar fcurve 1: raw (unannealed) unexposed, curve 2: raw (unannealed) exposed (1000 cGy)\}.

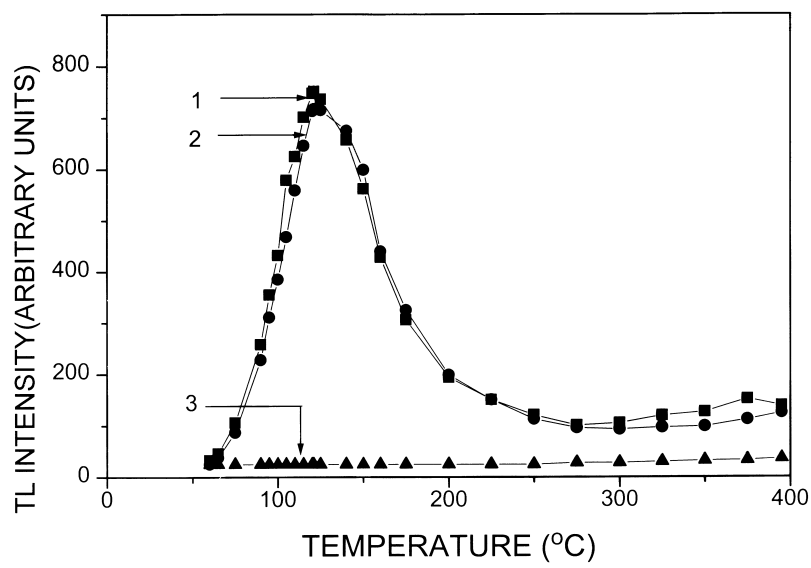

Figure 2. Glow curve of annealed feldspar \{curve 1: annealing at $500^{\circ} \mathrm{C}$ for $1 \mathrm{~h}$ and gamma exposed (1000 cGy), curve 2: annealing at $500^{\circ} \mathrm{C}$ for $5 \mathrm{~min}$ and gamma exposed (1000 cGy) and curve 3 : annealing at $500^{\circ} \mathrm{C} 1 \mathrm{~h} / 500^{\circ} \mathrm{C} 5 \mathrm{~min}$, unexposed $\}$. 
The TL recorded after 2, 6 and 13 days are marked as 3, 4 and 5, respectively. Fading rate is faster in first $24 \mathrm{~h}$ and the rate decays in subsequent days. The peak shift is also observed with time towards higher temperature side.

Figure 5 shows the quantitative fading (in terms of TL counts in micro coulomb) of raw and annealed exposed feldspar samples. For raw exposed sample (curve 1) there is no fading in integrated TL counts for 36 days, whereas annealed sample (curve 2) shows significant fading in first $24 \mathrm{~h}$ whereas the rate of fading is $40 \%$ and in subsequent time the fading is $7 \%$ per week. Any fading of TL counts in raw exposed feldspar samples is not observed due to reasons cited earlier. Thus, it is apparent that if annealed feldspar is used for personal or accident dosimetry, the TL should be recorded after $24 \mathrm{~h}$ of termination of exposure.

Figure 6 shows the dose response for raw gamma exposed feldspar. The TL response is linear from $500 \mathrm{cGy}$

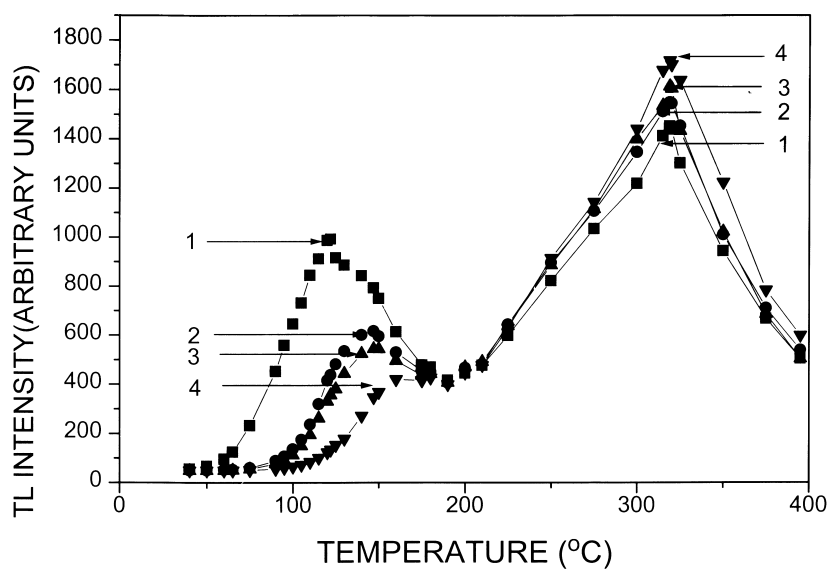

Figure 3. TL fading characteristics of raw exposed (1000 cGy) feldspar \{curve 1: raw exposed feldspar, curve 2: after 1 day fading, curve 3 : after 2 days fading and curve 4 : after 7 days fading .

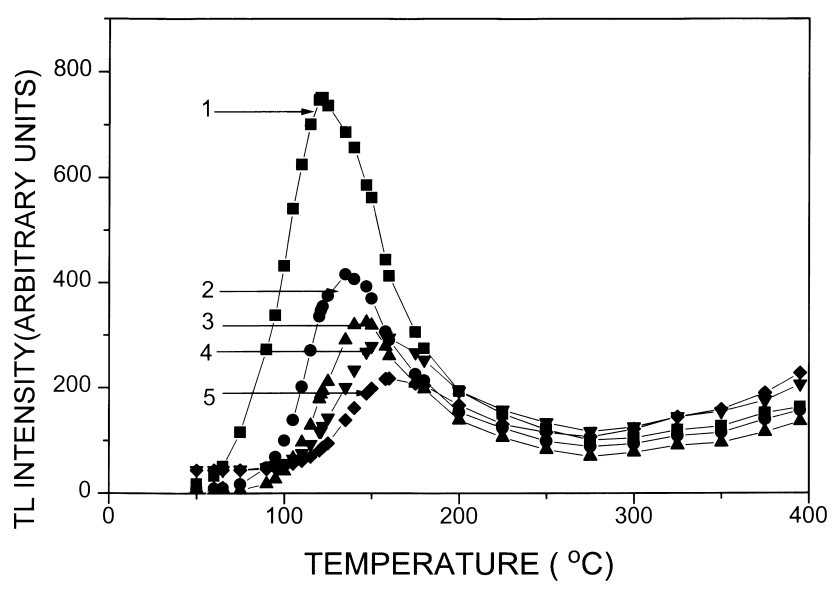

Figure 4. TL fading characteristics of annealed exposed (1000 cGy) feldspar \{curve 1: annealed exposed feldspar, curve 2: after 1 day fading, curve 3: after 2 days fading, curve 4 : after 6 days fading and curve 5: after 13 days fading . to $10^{5} \mathrm{cGy}$. The response is sublinear beyond $10^{5} \mathrm{cGy}$. Because of high background TL information in raw feldspar, appreciable change in TL response below $500 \mathrm{cGy}$ could not be measured statistically. The high gamma sensitivity and non-fading characteristics make raw feldspar a suitable material for gamma dosimetry beyond 500 cGy.

The TL response of annealed feldspar with dose is shown in figure 7 . It is observed that, the lower limit of detection using raw feldspar is about $500 \mathrm{cGy}$. The measurement limit can be brought down to $25 \mathrm{cGy}$ within $\pm 10 \%$ overall uncertainty, by annealing the feldspar. The sensitivity of annealed feldspar to gamma dose measurement is very close to that of raw feldspar. The TL response is linear from $25 \mathrm{cGy}$ to $1000 \mathrm{cGy}$ dose range. The feldspar is a commonly available natural material in the earth crust like quartz and sand etc. It is reported that an

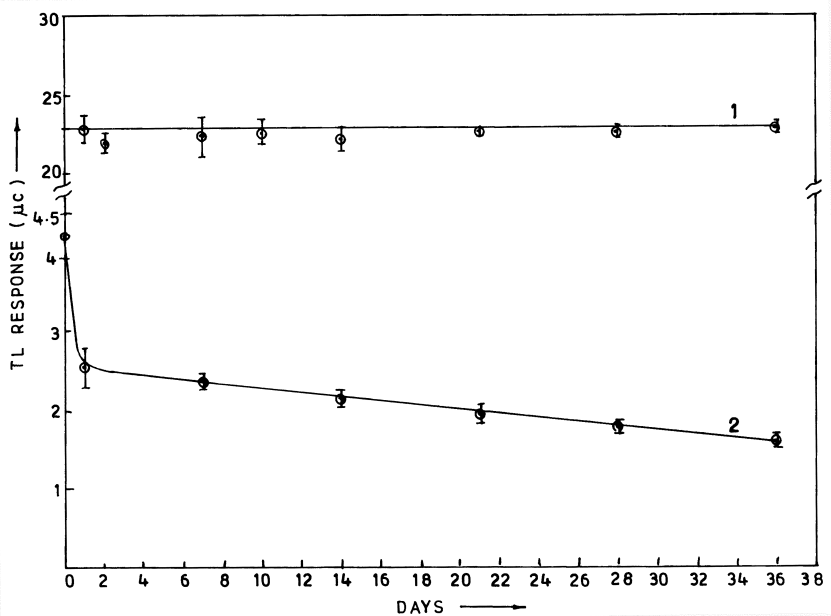

Figure 5. Quantitative fading of feldspar \{curve 1: raw feldspar exposed to $1000 \mathrm{cGy}$ and curve 2: annealed feldspar exposed to $1000 \mathrm{cGy}$.

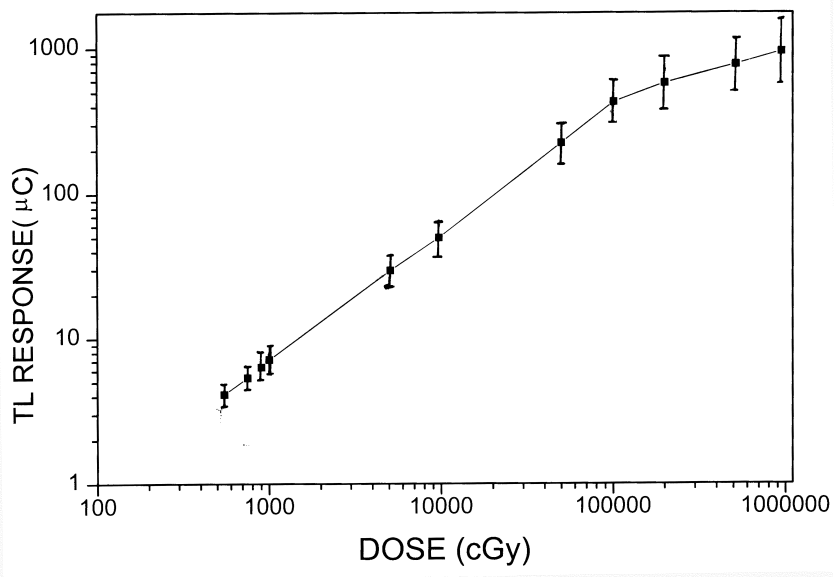

Figure 6. TL response vs dose of raw feldspar exposed from $1000 \mathrm{cGy}$ to $10^{6} \mathrm{cGy}$. 


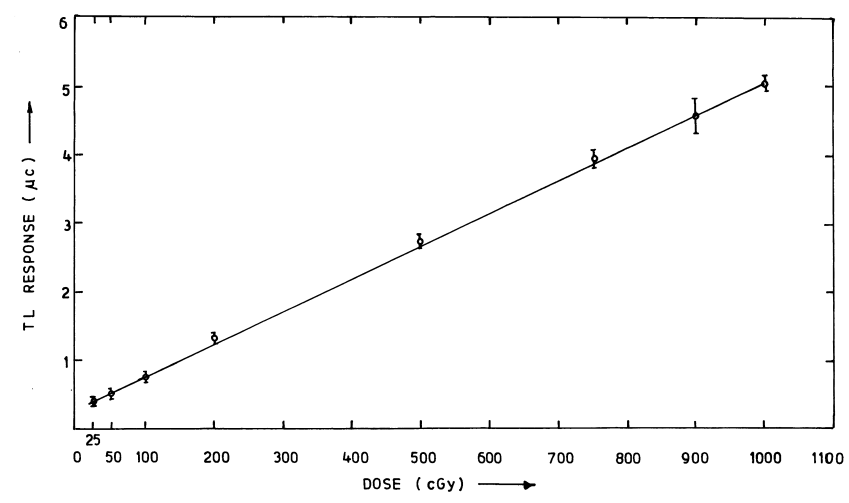

Figure 7. TL response vs dose of annealed feldspar.

accident dosimeter should have a linear response from $1 \mathrm{cGy}$ to $2000 \mathrm{cGy}$ having uncertainty less than $\pm 20 \%$ within one week of accident (Toshiyuki 1988). Thus the feldspar can also be used for personal accident dosimetry like other environmental materials with some limitations.

\section{Conclusions}

The raw potassium feldspar can be used for dosimetry beyond $500 \mathrm{cGy}$ because of non-fading nature. The same sample when annealed can measure even $25 \mathrm{cGy}$ dose provided the exposed sample is evaluated after $24 \mathrm{~h}$ from termination of exposure.

\section{Acknowledgements}

We are thankful to Dr Ram Gopal, Director, Defence Laboratory, Jodhpur and Mr P K Khatri, Head, Isotope Division, for encouragement and support to this work.

\section{References}

Clarke M I, Rendell H M, Sanchex-Munoz L and Garcia Guinea J 1997 Radiat. Meas. 27137

Duller G A T 1997 Radiat. Meas. 27663

Ichikawa Y and Tanida M 1969 Bull. Inst. Chem. Res. Kyoto Univ. 4723

Mejdahl V 1968 Thermoluminescence in shore sand. Ch. II of thermoluminescence of geological materials. Proceeding of NATO advanced research institute on applications of TL in geological problems (Academic Press) p. 453

Mejdahl V 1985 Nucl. Tracks 10133

Robertson G B, Prescott J R and Hutton J T 1991 Nucl. Tracks \& Radiat. Meas. 18101

Robertson G B, Prescott J R and Hutton J T 1993 Nucl. Tracks \& Radiat. Meas. 21245

Toshiyuki M 1988 Health Phys. 55951

Vaijapurkar S G and Bhatnagar P K 1993 Nucl. Tracks \& Radiat. Meas. 21267

Vaijapurkar S G, Raman R and Bhatnagar P K 1993 To study the thermoluminescence (TL) properties of sand and its use as a personal/accident dosimeter. Technical Report No. DLJ/TC/ IL/93/9. (DLJ: Defence Laboratory, Jodhpur)

Wintle A G 1974 Factors determining the thermoluminescence of chronologically significant materials, D Phil. Thesis, University of Oxford, Oxford, UK

Wintle A G 1977 J. Lumin. 15385 